\title{
Studi Tanda Atas Makna Pelesarian Lingkungan Sebagai Isu Utama Konten Kreatif Media Sosial
}

\author{
Finy Fitrya Basarah \\ Universitas Mercu Buana \\ Email : finy.basarah@mercubuana.ac.id \\ Jl. Meruya Selatan No. 1, Kembangan, Jakarta Barat 11650 \\ Telp.021-5840816/Fax.021-5840813
}

Submitted: 26 August 2019 Revised: 9 October 2019 Accepted: 11 October 2019

\begin{abstract}
ABSTRAK
Keseimbangan alam tidak terlepas dari perbuatan manusia, baik perbuatan yang merusak maupun yang mendukung pelestarian alam dan lingkungan. Pelestarian lingkungan dalam bentuk kampanye lingkungan hidup saat ini mulai bermunculan melalui media sosial dalam bentuk vlog atau video blogging. Dengan mempergunakan analisis semiotika Charles Sanders Peirce, riset ini bermaksud untuk mengungkapkan apa makna dibalik konten (teks) dalam vlog mengenai pelestarian lingkungan tersebut. Terdapat 3 (tiga) vlog yang dipilih dalam penelitian ini melalui YouTube.com. Hasil dari penelitian ini diantaranya adalah bahwa kesehatan merupakan investasi, kegiatan menyatu dengan alam bisa dilakukan secara bersama-sama, dan pelestarian lingkungan harus dijaga secara bersama-sama, tidak bisa dilakukan sendiri.
\end{abstract}

Kata kunci: media sosial, pelestarian lingkungan, vlog, wacana

\begin{abstract}
The balance of nature could not be separated from human interactions, both destructive acts and those that supported the conservation of nature and the environment. Nowadays, quite a lot of environmental issues through some campaign rises up via social media in the form of vlogs, or video blogging. By utilizing Charles Sanders Peirce's Semiotics Analysis, this research is done to uncover the meanings behind these environmental vlog contents. There are three vlogs chosen in this research, all of them are from YouTube.com. The results show that Health is an Investment, Conjoining with nature can be done together, and the conservation of environment cannot be done alone, and must be done together.
\end{abstract}

Keywords: discourse, environmental conservation, social media, vlog

\section{PENDAHULUAN}

Isu global warming atau pemanasan global bukanlah sesuatu hal yang baru muncul di permukaan dan menjadi pembicaraan masyarakat. Keprihatinan sebagian besar masyarakat mengenai pemanasan global yang menyebabkan lapisan ozon menjadi semakin menipis ini tentunya memberikan dampak yang negatif bagi manusia dan makhluk hidup lainnya.

Salah satu dampak negatifnya adalah suhu bumi yang semakin panas. Okjokull, sebuah glester yang pernah menjadi ikon Islandia, dinyatakan mati pada 2014 karena telah mencair. Padahal, dulu glester tersebut sempat membentang sejauh 15 kilometer persegi (https://www.liputan6.com/citizen6/read/4 042317/perubahan-iklim-itu-nyata-inipemakaman-untuk-glester-pertama-yangmencair-di-islandia. Diakses pada tanggal 16.09.19, pukul 09.02 WIB).

Selain itu diduga ada 7 (tujuh) bencana alam yang muncul akibat pemanasan gobal atau global warming ini, 
yaitu: kekeringan, hujan deras, banjir, kebakaran hutan, ikan semakin berkurang, panen yang buruk, dan topan dan badai salju

(https://wri-

indonesia.org/id/blog/negara-negara-

asean-harus-mengambil-tindakan-

bersama-untuk-menghadapi-perubahan-

iklim. Diakses pada 16.09.19, pukul 10.21 WIB)

Di wilayah Asia Tenggara sendiri, Indonesia bersama Negara-negara anggota ASEAN lainnya telah menyadari akibat dari global warming ini. Berdasarkan laporan terbaru dari Lembaga Hubungan Internasional Norwegia (NUPI), 'Impact of Climate Change on ASEAN International Affairs, 'adalah salah satu laporan pertama yang berfokus pada dampak perubahan iklim terhadap hubungan internasional ASEAN. Ditulis bersama-sama oleh wadah pemikir dan lembaga internasional di seluruh ASEAN (termasuk World Resources Institute Indonesia), laporan ini menyoroti kawasan yang perlu menjadi perhatian negara-negara anggota. Secara garis besar, laporan tersebut meliputi temuan-temuan, yaitu: Perubahan iklim dapat mengakibatkan krisis kemanusiaan, migrasi, dan/atau peningkatan kebutuhan impor kebutuhan dasar yang dapat mempengaruhi hubungan antar Negara, dan Mengurangi emisi gas rumah kaca membutuhkan koordinasi dan kerja sama internasional, termasuk di sektor energi (https://wri-indonesia.org/id/blog/negaranegara-asean-harus-mengambil-tindakanbersama-untuk-menghadapi-perubahaniklim. Diakses pada 16.09.19, pukul 10.21 WIB).

Badan dunia, Perserikatan BangsaBangsa (PBB) juga telah memiliki Konvensi Kerangka Kerja Perubahan Iklim Perserikatan Bangsa-
Bangsa (UNFCCC), yaitu perjanjian lingkungan internasional yang dirundingkan pada KTT Bumi di Rio de Janeiro pada tanggal 3 sampai 14 Juni 1992 dan diberlakukan tanggal 21 Maret 1994. Tujuan UNFCCC adalah "menstabilkan konsentrasi gas rumah kaca di atmosfer sampai tingkat yang mampu mencegah campur tangan manusia dengan sistem iklim". Kerangka kerja ini menentukan bagaimana perjanjian internasional tertentu dapat mengatur batas gas rumah kaca yang benar-benar mengikat

(https://id.wikipedia.org/wiki/Konvensi_K erangka_Kerja_Perubahan_Iklim_Perserik atan_Bangsa-Bangsa diakses pada 16.09.19, pukul 10.30 WIB).

Salah satu cara untuk memperlambat pemanasan global ini adalah dengan melestarikan alam dan lingkungan. Beberapa generasi muda hadir mengkampanyekan pelestarian lingkungan lewat vlog yang mereka publikasikan di media sosial YouTube.com.

Konten mengenai pelestarian lingkungan ini merupakan teks yang bisa dikaji lebih jauh. Mengutip tulisan Aris Badara disebutkan bahwa yang dimaksud dengan teks adalah wacana (lisan) yang difiksasikan oleh redaksi melalui suatu proses jurnalistik ke dalam bentuk tulisan yang isi, bahasa, dan strukturnya memenuhi kriteria bahasa media surat kabar. Adapun wacana ialah tulisan yang memiliki struktur berita yang berisi tentang suatu peristiwa yang dipublikasikan melalui surat kabar (Aris Badara, 2014).

Apabila dihubungkan dengan penelitian ini maka redaksi adalah pembuat konten $v$ log, dan walaupun tidak melalui suatu proses jurnalistik biasanya 
terdapat proses editing sebelum dipublikasikan. Publikasi yang dilakukan pun bukan melalui surat kabar (media cetak), melainkan melalui media sosial atau media online.

Peirce mengemukakan teori segitiga makna atau triangle of meaning yang terdiri atas tiga elemen utama, yaitu tanda (sign), objek, dan pengguna tanda (interpretant). Tanda adalah sesuatu yang berbentuk fisik, yang dapat ditangkap oleh pancaindra manusia sebagai sesuatu yang merujuk (merepresentasikan) hal lain di luar tanda itu sendiri. Tanda menurut Peirce terdiri atas simbol (tanda yang muncul dari kesepakatan), ikon (tanda yang muncul dari perwakilan fisik), dan indeks (tanda yang muncul dari hubungan sebab-akibat). Acuan tanda ini deisebut objek. Objek atau acuan tanda adalah konteks sosial yang menjadi referensi dari tanda atau sesuatu yang dirujuk tanda. Pengguna tanda (interpretant) adalah konsep pemikiran dari orang yang menggunakan tanda dan menurunkannya pada suatu makna tertentu atau makna yang ada dalam benak seseorang tentang objek yang ditujuk sebuah tanda. Hal yang terpenting dalam proses semiosis adalah mengupayakan agar makna muncul dari sebuah tanda ketika tanda itu digunakan orang saat berkomunikasi (Sukriyadi Sambas, 2016).

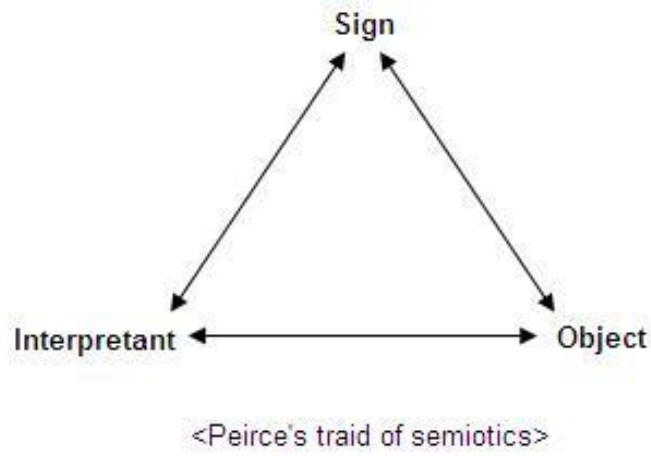

\section{Gambar 1 Triangle of Meaning Charles Sanders Peirce}

Wacana adalah praksis sosial dalam bentuk interaksi simbolis yang bisa terungkap dalam pembicaraan, tulisan, kial, gambar, diagram, film atau musik (N. Fairclough, 2010 dan M. Bloor \& Thomas, 2007 dalam Haryatmoko).

Analisis wacana atau analisis discourse dapat diaplikasikan pada semua teks, yakni pada "setiap permasalahan atau situasi atau konteks". Sejak analisis discourse dasarnya adalah interpretative dan dekonstruktif (deconstructing reading), maka tidak ada guideline atau pedoman metodologi khusus yang diikuti.
Tujuan analisis discourse adalah tidak menyediakan jawaban-jawaban yang pasti atau definitive, tetapi memberikan kepuasan (expand) horizon pemikiran dan interpretasi kita (Rachmah Ida, 2014).

Definisi dari media sosial itu sendiri yang berasal dari berbagai literatur penelitian (lihat Fuchs, 2014, dalam Nasrullah) salah satunya adalah Mandilbergh (2012), "Media sosial adalah media yang mewadahi kerja sama di antara pengguna yang menghasilkan konten (user-generated content)". 
Media sosial bermula dari internet. Internet sebagai media interaksi sosial telah terjadi di seluruh dunia, termasuk Indonesia. Perkembangan pengguna internet juga terus bertambah. Jumlah pengguna internet di Indonesia pun juga berkembang sangat pesat. Dalam waktu yang relatif singkat jumlah internet di Indonesia meningkat secara signifikan. Menurut data yang dipublikasikan oleh Republika.co.id (26 Agustus 2010), yang diambil pada tanggal 7 Oktober 2010, penggunaan internet di dunia mengalami kenaikan yang sangat signifikan (Shiefti Dyah, 2016).

Penelitian ini mengambil 3 (tiga) buah vlog yang bertemakan pelestarian lingkungan. Ketiga vlog tersebut kemudian akan dianalisa dengan mempergunakan analisis semiotika dari Charles Sanders Peirce guna mengetahui bagaimana makna dari balik teks yang ada pada vlog-vlog tersebut.

Memang tidak banyak vlogger yang mengkampanyekan pelestarian lingkungan apalagi yang secara teratur membuat konten yang mengangkat isu tentang global warming ini. Vlog-vlog tersebut dipilih secara acak dan kemudian dilihat tema yang diangkat yang memang berbeda-beda satu sama lain. Dikarenakan isu seperti ini memang jarang diangkat menjadi konten sebuah vlog dan dilakukan oleh generasi muda, maka dari itulah ketiga vlog tersebut menarik perhatian penelitian ini.
Tujuan riset ini adalah untuk mengetahui bagaimana makna pelestarian lingkungan sebagai isu utama konten kreatif media sosial (vlog).

\section{METODE PENELITIAN}

Pendekatan yang dianggap sesuai dengan riset ini adalah kualitatif. Penelitian kualitatif memiliki ciri-ciri, yaitu: 1) konteks dan setting alamiah (naturalistic); 2) bertujuan untuk mendapatkan pemahaman yang mendalam tentang suatu fenomena; 3) keterlibatan secara mendalam serta hubungan erat antara peneliti dengan subjek yang diteliti; 4) teknik pengumpulan data yang khas kualitatif tanpa adanya perlakuan (treatment) atau memanipulasi variabel; 5) adanya penggalian nilai (values) yang terkandung dari suatu perilaku; 6) bersifat fleksibel; dan 7) tingkat akurasi data dipengaruhi oleh hubungan antara peneliti dengan subjek penelitian (Haris Herdiansyah, 2013).

\section{HASIL DAN PEMBAHASAN \\ Vlog 1: Daffaa P melalui YouTube.com. Vlog berjudul "Pelestarian} lingkungan. Smpit Daarul Ilmi" berdurasi 4:19 menit ini sepertinya merupakan salah satu tugas sekolah SMPIT Daarul Ilmi Bandar Lampung, yang terdiri dari Afkar, Daffaa P, dan Hafidz R. Monolog dalam vlog ini melalui hasil editan agar tidak terlalu panjang.

Tabel 1 Tampilan Tulisan pada Pembuka Vlog Daffaa $\mathbf{P}$

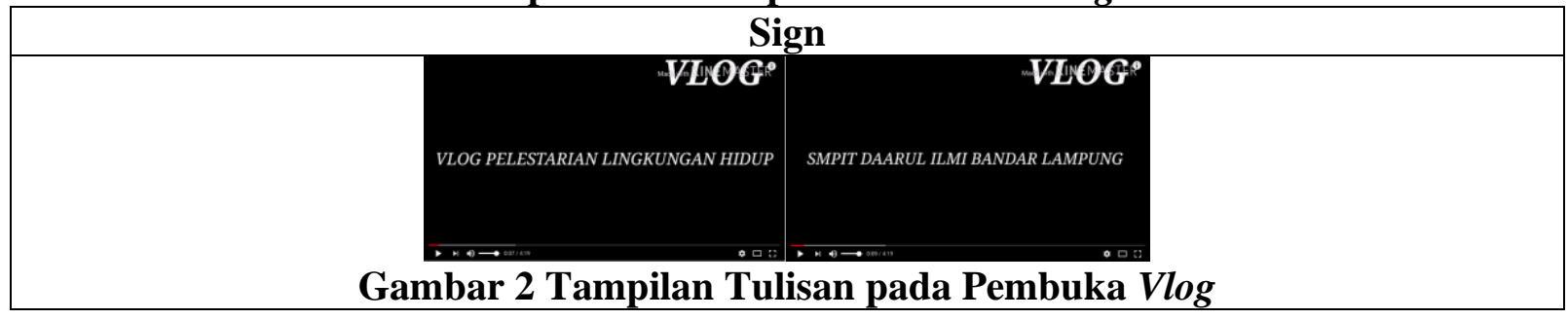




\begin{tabular}{|l|l|}
\hline \multicolumn{1}{|c|}{ Object } & \multicolumn{1}{|c|}{ Interpretant } \\
\hline Pelestarian lingkungan hidup & Latar hitam juga menunjukkan elegan dan \\
ketegasan bahwa hal tersebut memang perlu \\
dilakukan. Tulisan berwarna puth yang kontras \\
dengan warna hitam menunjukkan bahwa ini \\
merupakan sesuatu hal yang benar-benar harus \\
ditanggapi dengan serius. Tulisannya sendiri lebih \\
menunjukkan identitas, baik identitas konten vlog \\
maupun identitas pembuatnya. \\
\hline
\end{tabular}

Tabel 2 Pembuka Vlog Daffaa $P$

\begin{tabular}{|l|l|}
\hline \multicolumn{2}{|c|}{ Sign } \\
\hline $\begin{array}{l}\text { Monolog: } \\
\text { Assallaamualaikum warrahmatullahi wabarrakatuh. Pada kesempatan kali ini kami akan } \\
\text { membuat vlog tentang pelestarian lingkungan hidup. }\end{array}$ \\
\hline \multicolumn{2}{|c|}{ Object } \\
\hline $\begin{array}{l}\text { Pelestarian lingkungan hidup } \\
\text { Gambar } 3 \text { Pembuka Vlog }\end{array}$ \\
$\begin{array}{l}\text { Dua orang siswa SMP melakukan pembukaan atau } \\
\text { opening dalam vlog ini dengan mempergunakan } \\
\text { angle secara eye-level yang menunjukkan bahwa } \\
\text { baik siswa ini dengan viewers adalah equal atau } \\
\text { sejajar, sekaligus juga menunjukkan keakraban. }\end{array}$ \\
\hline
\end{tabular}

Tabel 3 Pesan dalam Konten Vlog Daffaa $\mathbf{P}$

\begin{tabular}{|c|c|}
\hline \multicolumn{2}{|r|}{ Sign } \\
\hline $\begin{array}{l}\text { Gambar } 4 \mathbf{P} \\
\text { Monolog: } \\
\text { Kita ketahui pembangunan di kota } \mathrm{I} \\
\text { perubahan zaman yang sangat sangat di } \\
\text { hutan tapi sekarang pembangunan perur } \\
\text { dalam bidang lingkungan mengakib } \\
\text { pembangunan yang begitu pesat itu me } \\
\text { harus diimbangkan dengan pelestarian li }\end{array}$ & $\begin{array}{l}\text { san dalam Konten Vlog } \\
\text { andar Lampung ini begitu pesat seiring dengan } \\
\text { amis dan modern. Kita lihat di belakang ini dulunya } \\
\text { ahan. Kita lihat pembangunan yang tidak signifikan } \\
\text { tkan lingkungan itu tercemar. Tapi memang } \\
\text { guntungkan sekali bagi ekonomi Negara kita. Tapi } \\
\text { gkungan. }\end{array}$ \\
\hline Object & Interpretant \\
\hline $\begin{array}{l}\text { Pembangunan dan hubungan dengan } \\
\text { pelestarian lingkungan }\end{array}$ & $\begin{array}{l}\text { Siswa ini mempergunakan angle kamera secara } \\
\text { Low (looking-down), di mana ia ingin } \\
\text { mengikutsertakan pemandangan perumahan yang } \\
\text { ada di depannya. Posisi angle ini menunjukkan } \\
\text { bahwa kedudukan viewers yang lebih tinggi dan }\end{array}$ \\
\hline
\end{tabular}




\begin{tabular}{|l|l|}
\hline & seharusnya bisa mengambil sikap dan tindakan \\
atas apa yang terjadi. Siswa ini menunjukkan \\
bahwa dia tidak memiliki kekuasaan atas \\
pembangunan yang terjadi di kotanya. Sementara \\
dalam monolognya siswa ini tidak \\
mempermasalahkan adanya pembangunan dan \\
modernisasi asalkan diimbangi dengan pelestarian \\
lingkungan.
\end{tabular}

\section{Tabel 4 Pesan dalam Konten Vlog Daffaa P 2}

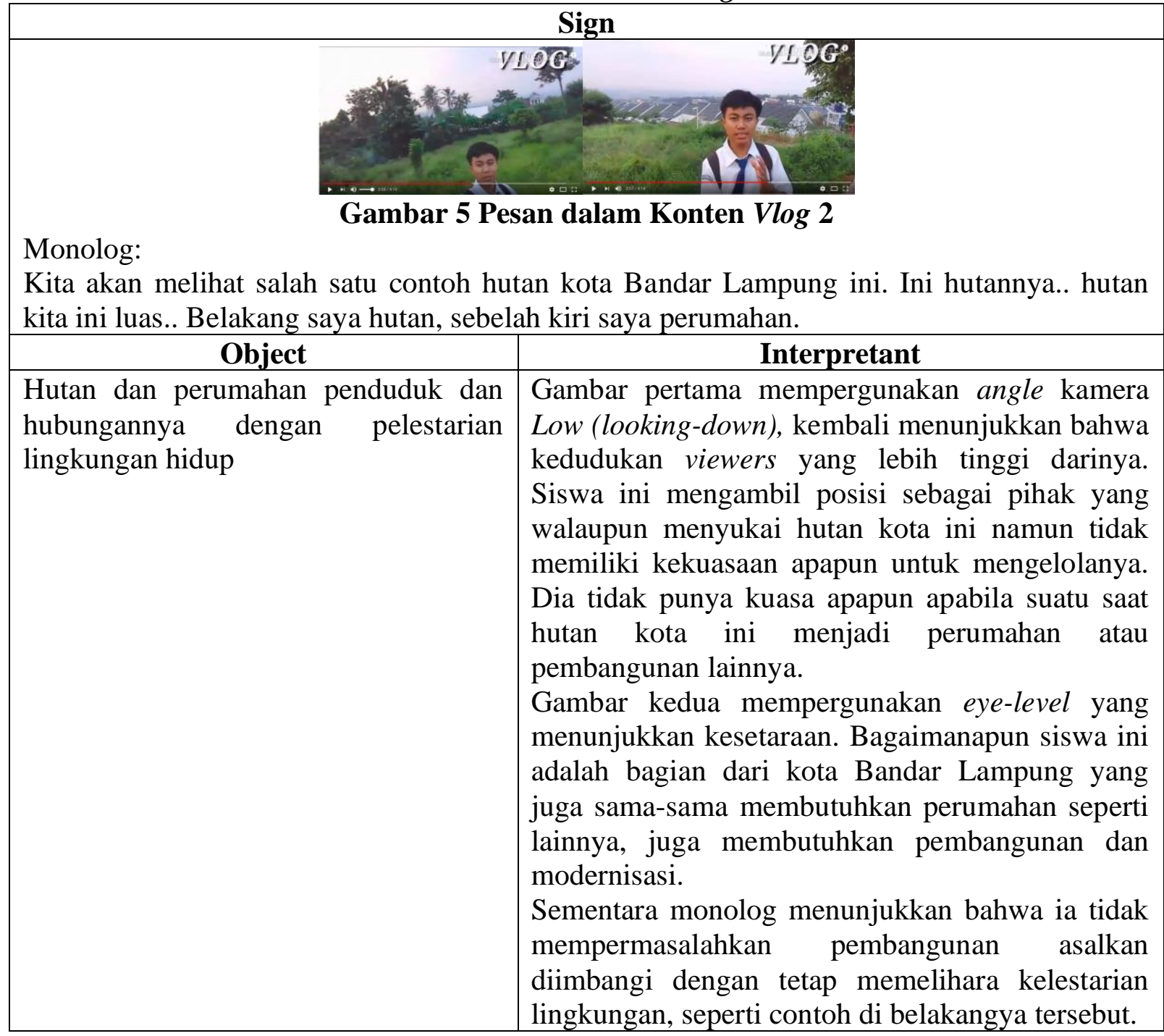

Tabel 5 Pesan dalam Konten Vlog Daffaa P 3

\begin{tabular}{|l|l|}
\hline & Sign \\
Monolog: \\
Bagaimana ketika semua CO2 pindah ke sini dan diserap oleh hutan kota menjadi oksigen \\
bagi kota Bandar lampung yang moga-moga menjadi kota sehat, damai, dan sejahtera! Dan
\end{tabular}


inilah insya Allah akhir dari perjalanan kita menyusuri hutan kota Bandar Lampung, semoga ini dapat menjadi pelajaran kita jangan semena-mena terhadap pembangunan, nggak apa-apa kotanya itu sepi yang penting hutannya masih luas (ketawa)

\begin{tabular}{|c|c|}
\hline Object & Interpretant \\
\hline $\begin{array}{llr}\text { Pembangunan } & \text { kota } & \text { modern dan } \\
\text { hubungannya dengan } & \text { pelestarian } \\
\text { lingkungan hidup } & & \end{array}$ & $\begin{array}{l}\text { Kedua gambar diambil secara eye-level ditambah } \\
\text { dengan posisi tangan diacungkan memberi } \\
\text { semangat ajakan bagi viewers. Ajakan ini } \\
\text { menunjukkan bahwa semua orang, khususnya } \\
\text { viewers, bisa ikut menjaga pelestarian lingkungan } \\
\text { tersebut, bisa tetep menjaga keseimbangan antara } \\
\text { pembangunan dan modernisasi dengan tetap } \\
\text { memelihara lingkungan supaya tercipta lingkungan } \\
\text { yang sehat. }\end{array}$ \\
\hline
\end{tabular}

Tabel 6 Penutup dalam Konten Vlog Daffaa $P$

Monolog:

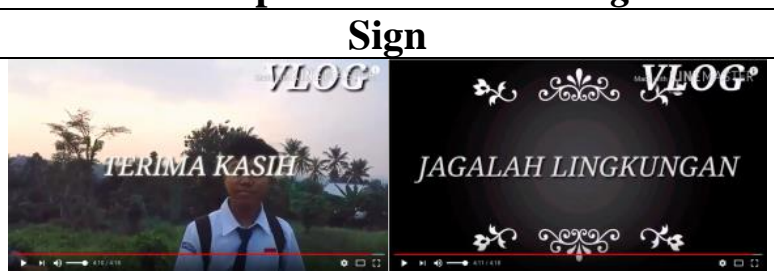

\section{Gambar 7 Penutup dalam Konten Vlog}

Salam sejahtera, terima kasih, wassallaamualaikum warrahmatullahi wabarakatuh..

\begin{tabular}{|l|l|}
\hline \multicolumn{1}{|c|}{ Object } & \multicolumn{1}{|c|}{ Interpretant } \\
\hline $\begin{array}{l}\text { Penutup dan ajakan untuk melestarikan } \\
\text { lingkungan hidup }\end{array}$ & $\begin{array}{l}\text { Gambar yang disertai tulisan "Terima Kasih" } \\
\text { dengan posisi angle secara eye-level menunjukkan } \\
\text { bahwa baik siswa ini, seluruh tim, dan viewers bisa } \\
\text { secara bersama-sama menjaga pelestarian } \\
\text { lingkungan. } \\
\text { Pesan terakhir dengan latar hitam yang } \\
\text { menunjukkan ketegasan dan tulisan berwarna } \\
\text { putih yang kontras dengan latar sekaligus } \\
\text { menunjukkan ajakan kepada semua viewers bahwa } \\
\text { menjaga kelestarian lingkungan merupakan hal } \\
\text { serius yang bisa dilakukan bersama. }\end{array}$ \\
\hline
\end{tabular}

Vlog 2: Hybid Maxxx melalui YouTube.com.

Vlog berdurasi 3.14 menit ini berjudul: [Geografi] Upaya Pelestarian Lingkungan Hidup. Kemungkinan vlog ini juga merupakan tugas sekolah, walaupun tidak disebutkan nama sekolahnya.
Monolog dalam vlog ini juga melalui proses edit, dan posisi kamera yang terlihat sama, gaya para siswa yang secara bergantian menyampaikan pesan, dan juga tema latar yang sama, akan disatukan dalam satu tabel. 
Tabel 7 Pembuka dalam Konten Vlog Hybid Maxxx

\begin{tabular}{|l|l|}
\hline \multicolumn{2}{|c|}{ Gambar 8 Pembuka dalam Konten Vlog Hybid Maxxx } \\
Monolog: \\
$\begin{array}{l}\text { Hai guys, ketemu lagi sama (menyebutkan nama satu persatu), kali ini kita bakal belajar } \\
\text { tentang pelestarian lingkungan hidup. }\end{array}$ \\
\hline \multicolumn{3}{|c|}{ Object } & \multicolumn{1}{c|}{ Interpretant } \\
\hline Pelestarian lingkungan secara umum & $\begin{array}{l}\text { Gambar ini posisi angle secara eye-level } \\
\text { menunjukkan bahwa baik para siswa ini dan } \\
\text { viewers adalah equal, sejajar. Artinya kita secara } \\
\text { bersama-sama bisa turut serta melestarikan } \\
\text { lingkungan. Ditunjang dengan kalimat ajakan } \\
\text { dalam monolog yang diucapkan oleh mereka, } \\
\text { sambil belajar sambil mengajak viewers untuk } \\
\text { sama-sama melestarikan lingkungan. Pada latar } \\
\text { terdapat bendera Republik Indonesia yang secara } \\
\text { tidak langsung menunjukkan identitas bangsa. }\end{array}$ \\
\hline
\end{tabular}

Tabel 8 Penampilan Hasbi, Naufal, dan Dzaky dalam Konten Vlog Hybid Maxxx

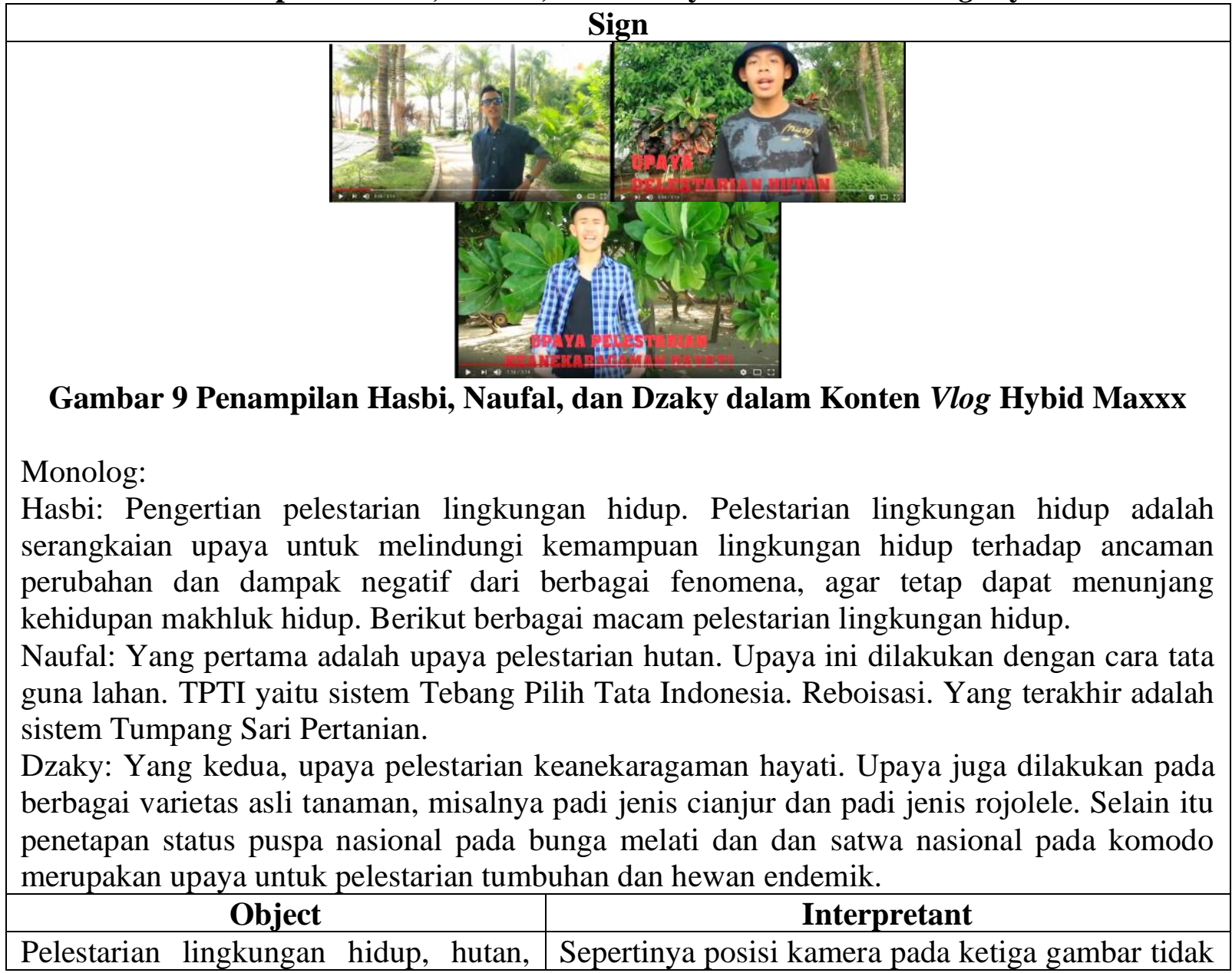




\begin{tabular}{|l|l|}
\hline dan keanekaragaman hayati & $\begin{array}{l}\text { terlalu eye-level namun juga tidak high (looking- } \\
\text { up) bisa saja posisi Hasbi yang agak } \\
\text { mendongakan kepalanya sedikit ke atas, dan } \\
\text { Naufal dan Dzaky yang agak menunduk karena } \\
\text { posisi kamera yang lebih rendah. Baik Hasbi, } \\
\text { Naufal, dan Dzaky terlihat percaya diri dengan } \\
\text { mata yang manatap ke arah kamera dan tangan } \\
\text { Hasbi yang sesekali diletakkan di pinggang. Hasbi, } \\
\text { Naufal, dan Dzaky terlihat yakin bahwa apa yang } \\
\text { akan disampaikan olehnya dan juga teman- } \\
\text { temannya akan bermanfaat untuk orang banyak. } \\
\text { Ditambah dengan latar tumbuh-tumbuhan } \\
\text { berwarna hijau menambah makna ajakan bahwa } \\
\text { suasana yang demikian asri merupakan suasana } \\
\text { yang bisa memberikan kehidupan yang jauh lebih } \\
\text { baik dan lebih sehat, selain apa yang disampaikan } \\
\text { oleh Naufal dan Dzaky juga berhubungan dengan } \\
\text { tanaman. Sedangkan warna merah sebagai tulisan } \\
\text { pendukung menunjukkan semangat dan keyakinan } \\
\text { bahwa hal tersebut bisa diwujudkan. }\end{array}$ \\
\hline
\end{tabular}

Tabel 9 Penampilan Mario, Hariz, dan Surya Konten Vlog Hybid Maxxx 2

\begin{tabular}{l}
\hline \\
Gambar 10 Penampilan Mario, Hariz, dan Surya Konten Vlog Hybid Maxxx 2 \\
Monolog: \\
Mario: Yang ketiga, upaya pelestarian tanah dan air. Dapat dilakukan dengan cara mencegah \\
pencemaran, merawat pintu-pintu air, menghemat air, dan keanekaragaman laut harus dijaga \\
kelestariannya. Upaya untuk mencegah pencemarannya adalah dengan cara Program Kali \\
Bersih atau Prokasih. \\
Hariz: Keempat, upaya pelestarian udara. Upaya pelestarian udara dilakukan dengan \\
mengharuskan pabrik melakukan penyaringan udara. Penambahan Ruang Terbuka Hijau \\
(RTH) dan hutan kota juga diperlukan. Selain itu juga harus uji emisi buat kendaraan \\
bermotor. \\
Surya: upaya pelestarian sumber daya udara bisa dilakukan dengan cara berikut: Pertama \\
tidak menggunakan semprotan yang mengandung CFC; kedua menggunakan penyaring di \\
kendaraan bermotor; ketiga tidak menggunakan alat pendingin yang menggunakan Freon; \\
keempat mengurangi penggunaan sumber daya alam yang tidak dapat diperbaharui, kelima \\
menghemat penggunaan kertas; keenam melakukan reboisasi atau penghijauan; ketujuh \\
menggunakan air sehemat mungkin, kedelapan memilah sampah menurut jenisnya. \\
\hline \multicolumn{1}{c}{ Object } \\
Pelestarian lingkungan tanah dan udara Posisi kamera eye-level menunjukkan kesetaraan, \\
bahwa baik mereka maupun viewers bisa secara
\end{tabular}




\begin{tabular}{|l|l|}
\hline & bersama-sama melakukan apa yang mereka \\
sampaikan. Latar pantai mendukung apa yang \\
disampaikan. Pantai bersih terpelihara bisa \\
diwujudkan salah satunya dengan menjaga \\
kelestarian lingkungan. Mario dan Hariz posisi \\
mata menatap kamera, namun tidak dengan Surya. \\
Surya terlihat tidak lebih percaya diri \\
dibandingkan dengan kedua rekannya ataupun \\
yang lainnya. Warna merah sebagai tulisan \\
pendukung juga menunjukkan semangat dan \\
keyakinan bahwa hal tersebut bisa diwujudkan, \\
sedangkan warna coklat muda untuk kata "tanah" \\
dan biru untuk kata "air" sebagai warna dari \\
elemen yang bersangkutan (tanah dan air).
\end{tabular}

Tabel 10 Penutup dalam Konten Vlog Hybid Maxxx

Monolog:

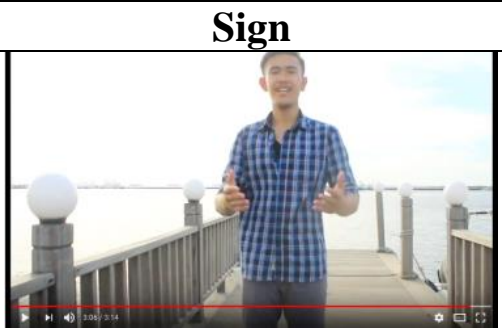

Gambar 11 Penutup dalam Konten Vlog Hybid Maxxx

Dzaky: Sekian pembelajaran kali ini dari kelompok kami, kurang lebihnya mohon maaf, wassallaamualaikun warrahmatullaahi wabarrakatuh.

\begin{tabular}{|c|c|}
\hline Object & Interpretant \\
\hline $\begin{array}{l}\text { Ajakan untuk ikut melestarikan } \\
\text { lingkungan hidup }\end{array}$ & $\begin{array}{l}\text { Posisi kamera high (looking-up) menunjukkan } \\
\text { power, artinya Dzaky mewakili teman-teman satu } \\
\text { kelompoknya mempunyai pengaruh untuk bisa } \\
\text { mengajak viewers melakukan apa yang telah } \\
\text { mereka sampaikan pada vlog. Dengan latar } \\
\text { dermaga pantai menunjukkan suasana yang segar } \\
\text { yang bisa terwujud apabila kelestarian lingkungan } \\
\text { tetap dapat dipelihara. }\end{array}$ \\
\hline
\end{tabular}

\section{Vlog 3: Inthan_kartika punya melalui YouTube.com.}

Dalam vlog berdurasi 1:36 detik ini, Inthan memberikan materi mengenai "Media pembelajaran IPS ,\#vlog 1 tentang lingkungan buatan". Lingkungan buatan termasuk salah satu cara memelihara lingkungan hidup karena dikondisikan agar manusia ataupun makhluk lainnya bisa merasa nyaman dan aman. Lokasi tempat pengambilan vlog adalah di Purwokerto. Inthan membuat vlog dengan cara berjalan menelusuri salah satu kawasan pemukiman di desa Waduk Waluh, Purwokerto. Pengambilan angle kamera yang sama akan disatukan dalam satu tabel. Monolog juga mengalami proses edit. 
Tabel 11 Tampilan Awal dalam Konten Vlog Inthan_kartika punya

\begin{tabular}{|c|l|}
\hline \multicolumn{2}{|c|}{ Sign } \\
\hline \multicolumn{1}{|c|}{ Gambar 12 Pembuka dalam Konten Vlog Inthan_kartika punya } \\
\hline \multicolumn{1}{|c|}{ Object } & \multicolumn{1}{|c|}{ Interpretant } \\
\hline $\begin{array}{l}\text { Lingkungan buatan sebagai salah satu } \\
\text { cara melestarikan lingkungan }\end{array}$ & $\begin{array}{l}\text { Tulisan ini awalnya berlatar abu-abu kemudian } \\
\text { hijau. Warna tulisan putih menunjukkan bersih, } \\
\text { suci, artinya bisa dimaknai sebagai apa yang akan } \\
\text { disampaikan memiliki maksud dan tujuan yang } \\
\text { baik. } \\
\text { Warna abu-abu bisa dimaknai sebagai sesuatu } \\
\text { yang serius. Warna abu-abu juga termasuk warna } \\
\text { alam. Warna hijau juga warna alam, menunjukkan } \\
\text { keasrian. Perubahan warna menunjukkan bahwa } \\
\text { kedua warna tersebut, warna alam, sangat } \\
\text { berhubungan dengan lingkungan hidup. }\end{array}$ \\
\hline
\end{tabular}

Tabel 12 Pembuka dalam Konten Vlog Inthan_kartika punya

\begin{tabular}{|c|c|}
\hline \multicolumn{2}{|r|}{ Sign } \\
\hline \multicolumn{2}{|c|}{$\begin{array}{l}\text { Gambar } 13 \text { Pembuka dalam Konten Vlog Inthan_kartika punya } \\
\text { Ialaikum warrahmatullahi wabarrakatuh.. perkenalkan nama saya Inthan Kartika } \\
\text { i saya akan menjelaskan salah satu materi dari kelas } 3 \text { semester } 2 \text { yaitu tentang } \\
\text { buatan. Sebelumnya temen } 2 \text { tau ngga sih apa yang dimaksud dengan lingkungan } \\
\text { ngkungan buatan merupakan segala sesuatu yang dibuat sengaja oleh manusia } \\
\text { juan tertentu. Adapun contoh dari lingkungan buatan seperti pemukiman } \\
\text { lahan pertanian, lahan perkebunan, waduk, tambak, dan lain2 sebagainya. }\end{array}$} \\
\hline Object & Interpretant \\
\hline $\begin{array}{l}\text { Lingkungan buatan sebagai salah satu } \\
\text { cara melestarikan lingkungan hidup }\end{array}$ & $\begin{array}{l}\text { Posisi kamera low (looking-down) } \\
\text { menunjukkan bahwa Inthan ini kurang percaya } \\
\text { diri, namun bisa juga sekaligus ingin menunjukkan } \\
\text { suasana tempat yang berhubungan dengan materi } \\
\text { yang akan ia sampaikan. Adapun lingkungan } \\
\text { buatan yang dimaksud intinya untuk keselarasan } \\
\text { ekosistem dan kehidupan makhluk hidup. } \\
\text { Posisi mata yang ditujukan ke arah kamera } \\
\text { memperlihatkan kontak mata yang baik dengan } \\
\text { viewers sekaligus kesungguhan dalam } \\
\text { menyampaikan materi. }\end{array}$ \\
\hline
\end{tabular}


Tabel 13 Pesan dalam Konten Vlog Inthan_kartika punya

Monolog:

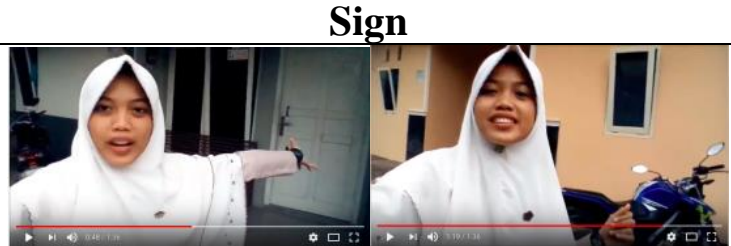

Gambar 14 Pesan dalam Konten Vlog Inthan_kartika punya

Nah, sekarang saya sudah berada di salah satu desa di Waduk Waluh tepatnya di Purwokerto. Di belakang saya merupakan pemukiman penduduk di mana pemukiman penduduk ini merupakan salah satu contoh yang telah saya sebutkan tadi. Nah, pemukiman penduduk ini dibuat secara sengaja oleh manusia dengan tujuan tertentu yaitu sebagai tempat tinggal manusia. Karena dengan adanya rumah ini manusia itu dapat terlindungi dari binatang buas, dari teriknya sinar matahari, dari hujan, dari dingin, dan lain2 sebagainya.

Object

Lingkungan buatan di salah satu desa Waduk Waluh sebagai salah satu upaya pelestarian lingkungan

\section{Interpretant}

Posisi kamera masih low (looking-down) dengan kontak mata yang baik walau sesekali melihat apa yang dia tunjukkan kepada viewers. Latar menunjukkan, seperti yang dia utarakan, yaitu contoh pemukiman penduduk sebagai lingkungan buatan. Tampak warna tembok yang cerah yang bisa memberikan rasa senang dan gembira bagi yang melihat terutama penghuninya.

Tabel 14 Penutup dalam Konten Vlog Inthan_kartika punya

Monolog:

\section{Gambar 15 Penutup dalam Konten Vlog Inthan_kartika punya}

Mungkin demikian materi yang dapat saya sampaikan semoga bermanfaat sampai jumpa di vlog berikutnya.. dadah.. Wassallaamualaikum warrahmatullaahi wabarrakatuh..

\begin{tabular}{|c|c|}
\hline Object & Interpretant \\
\hline $\begin{array}{l}\text { Ajakan untuk ikut melestarikan } \\
\text { lingkungan hidup }\end{array}$ & $\begin{array}{l}\text { Posisi kamera masih low (looking-down) dengan } \\
\text { kontak mata yang tetap baik. Di sini Inthan } \\
\text { melambaikan tangannya dan tetap tersenyum } \\
\text { menunjukkan keramahan sekaligus keakraban. } \\
\text { Tulisan di akhir dengan latar yang sama seperti di } \\
\text { awal bermakna sama; warna alam (hijau) yang } \\
\text { berhubungan dengan lingkungan dan warna putih } \\
\text { sebagai sesuatu yang bersih, yang baik. }\end{array}$ \\
\hline
\end{tabular}

Ketiga vlog tersebut memang tidak ada yang menyinggung secara langsung mengenai efek rumah kaca yang menjadi agenda utama dari Konvensi Kerangka Kerja Perubahan Iklim Perserikatan
Bangsa-Bangsa (UNFCCC). Namun, walaupun demikian, setidaknya ketiga $v$ log tersebut bisa mewakili generasi muda atau "Gen Y" yang saat ini ternyata mampu memberikan perhatian bagi 
keberlangsungan lingkungan hidup. Apa yang mereka tampilkan di vlog mereka, baik itu merupakan tugas sekolah maupun lainnya, menunjukkan bahwa mereka memiliki kesadaran dan rasa percaya diri bahwa seluruh masyarakat Indonesia khususnya akan mampu memelihara lingkungan.

3 (tiga) vlog tepilih tidak hanya menyampaikan apa yang mereka pikirkan namun juga memberikan visualisasi mengenai keadaan lingkungan di Indonesia saat ini. Walaupun mereka menampilkan hal yang baik (tidak memberikan visualisasi mengenai kerusakan lingkungan) namun setidaknya mereka mampu memberikan contoh agar viewers tertarik untuk tetap memelihara lingkungan yang sudah baik tersebut.

Ketiga vlog menyadari adanya kesetaraan dengan viewers, yang artinya mereka sadar bahwa masalah pelestarian lingkungan ini adalah masalah bersama, harus dilestarikan secara bersama-sama, bukan hanya pihak-pihak tertentu saja yang diharapkan bisa menjaga lingkungan ini. Beberapa orang dalam vlog tersebut memang terlihat kurang percaya diri, artinya bahwa sebetulnya mereka juga butuh dukungan dari masyarakat luas, khususnya viewers, karena tidak mungkin pelestarian lingkungan tersebut hanya mereka yang memelihara, yang menjaga. Mereka membutuhkan dukungan bersama dari seluruh masyarakat.

Ketiga vlog mengambil gambar di luar ruangan. Hal tersebut sekaligus ajakan kepada viewers untuk selalu dekat dengan alam, menyatu dengan alam. Alam yang belum terkena campur tangan manusia.

Pilihan warna dalam vlog-vlog ini adalah warna-warna alam. Hal tersebut sangat sesuai dengan tema mengenai pelestarian lingkungan ini. Pilihan warna alam artinya kembali ke alam atau "Back to Nature". Pilihan warna yang sederhana ini juga menunjukkan bahwa apa yang mereka sampaikan dan ajakan mereka tersebut bukan merupakan hal yang mustahil untuk dilakukan, itu merupakan sesuatu yang simple, yang sederhana, yang bisa dilakukan oleh semua orang.

Keseimbangan pada vlog pertama bisa dimaknai bahwa tidak ada salahnya modernisasi itu, karena pada dasarnya manusia membutuhkan perumahan karena itu bagian dari kebutuhan. Namun, jangan melupakan hidup yang tetap sehat dan bersih dengan menjaga kelestarian lingkungan, menjaga hutan kota, supaya masyarakat yang tinggal di sekitarnya, khususnya di perumahan tersebut tetap dapat menghirup udara yang bersih dan sehat, karena bagaimanapun hidup sehat jauh lebih penting dan, selain properti dan industri, kesehatan juga merupakan investasi jangka panjang.

Visualisasi pada vlog kedua bisa dimaknai bahwa suasana seperti itu masih sangat dibutuhkan terutama oleh siswasiswa tersebut. Bukan pantai yang kotor ataupun tanaman yang rusak yang mereka impikan. Ini juga diharapkan ke depannya akan tetap terus seperti itu. Mereka sebagai generasi muda masih memimpikan menikmati kondisi seperti itu, bukan hanya untuk mereka saat ini, namun juga untuk generasi yang akan datang.

Tema "Lingkungan Buatan" pada vlog ketiga atau terakhir bisa dimaknai bahwa kita sebagai manusia, sebagai masyarakat, bisa menciptakan lingkungan yang asri, apabila kita memang bisa. Bisa di sini dapat diartikan bukan saja mampu, tapi juga mau. Lingkungan yang asri akan memberikan udara bersih dan kehidupan 
yang jauh lebih baik, yang sehat. Selain itu lokasi yang dipilih, yaitu Waduk Waluh, Purwokerto, bisa sekaligus sebagai contoh dan promosi bagi masyarakat, khususnya viewers.

Jadi, keseluruhan vlog yang merupakan ajakan untuk memelihara lingkungan sekaligus mengajak hidup sehat ini memang disampaikan dengan cara dan gaya yang berbeda-beda. Ada yang mengajak secara bersama-sama untuk memelihara lingkungan, ada juga yang seolah meminta bantuan kepada seluruh masyarakat karena bagaimanapun hal tersebut akan lebih baik dilakukan secara bersama-sama, tidak hanya sendiri.

\section{SIMPULAN}

Salah satu isu global warming adalah kehadiran rumah kaca yang memang menjadi agenda utama dari Konvensi Kerangka Kerja Perubahan Iklim Perserikatan BangsaBangsa (UNFCCC). Konten pelestarian lingkungan dalam ketiga vlog memang tidak berhubungan langsung dengan efek rumah kaca, namun, mereka berharap adanya keseimbangan antara alam dan modernisasi, di mana alam yang asri dan bersih secara langsung akan menciptakan iklim yang juga bersih.

Pada vlog pertama ada keseimbangan, karena baik tempat tinggal yang layak dan lingkungan yang sehat sama-sama merupakan kebutuhan, samasama merupakan investasi jangka panjang. Di sini vlogger mengajak seluruh masyarakat, khususnya viewers, untuk turut menjaga kelestarian lingkungan, karena hal tersebut tidak mungkin dilakukannya sendiri.

Siswa-siswa pada vlog kedua mengajak viewers untuk bersama-sama turut menjaga kelestarian lingkungan, bersama-sama menyatu dengan alam, menjaga keseimbangan alam. Bersama pasti bisa.

Vlog terakhir dengan tema lingkungan buatan menunjukkan bahwa kalau kita bisa, kita pasti memiliki lingkungan yang asri dan selaras dengan kehidupan manusia itu sendiri. Di sini vlogger juga mengharapkan dukungan karena ia tidak mungkin melakukannya sendiri.

Secara umum vlog-vlog ini ingin mengajak semua viewers untuk senantiasa bersama-sama menjaga lingkungan demi masa depan yang lebih baik khususnya kesehatan, karena apabila kita memiliki kesehatan yang baik otomatis kita bisa beraktivitas dengan baik.

\section{UCAPAN TERIMA KASIH}

Puji syukur kehadirat Allah SWT, Universitas Mercu Buana khususnya Lembaga Puslit untuk sumber pendanaan Riset TA 2017/2018, Fakultas Ilmu Komunikasi Universitas Mercu Buana Meruya, dan Fakultas Ilmu Komunikasi Universitas Budi Luhur atas kesempatan yang diberikan untuk memfasilitasi luaran riset ini.

\section{DAFTAR PUSTAKA}

Alyusi, Shiefti Dyah. (2016). Media Sosial: Interaksi, Identitas dan Modal Sosial. Jakarta: Kencana Prenada Media Grup.

Badara, Aris. (2014). Analisis Wacana: Teori, Metode, dan Penerapannya pada Wacana Media. Jakarta: Kencana Prenada Media Grup.

Firdaus, Wildan Maulana, Kokom Komariah, dan Centurion Chandratama Priyatna. (2017). Representasi Nilai Kesempurnaan, Kesatuan, dan Keberanian Pada Logo Baru PT. Darta 
Media Indonesia (Kaskus.co.id) (Studi Analisis Semiotik Charles Sanders Peirce Mengenai Logo Baru PT Darta Media Indonesia (Kaskus.co.id) Sebagai Corporate Identity Perusahaan). Semiotika: Jurnal Komunikasi Vo. 11 No. 1. Universitas Bunda Mulia.

Haryatmoko. (2017). Critical Discourse Analysis (Analisis Wacana Kritis). Landasan Teori, Metodologi, dan Penerapan. Jakarta: PT RajaGrafindo Persada.

Herdiansyah, Haris. (2013). Wawancara, Observasi, dan Focus Groups Sebagai Instrumen Penggalian Data Kualitatif. Jakarta: PT RajaGrafindo Persada.

Ida, Rachmah. (2014). Metode Penelitian, Studi Media dan Kajian Budaya. Jakarta: Kencana Prenada Media Group. Nasrullah, Rully. (2016). Media Sosial, Perspektif Komunikasi, Budaya, dan Sosioteknologi. Bandung: PT Remaja Rosdakarya.

Sambas, Syukriadi. (2016). Antropologi Komunikasi. Bandung, CV Pustaka Setia.

Susanto, Eko Harry. Media Sosial sebagai Pendukung Jaringan Komunikasi Politik. Jurnal Aspikom Vol. 3 Nomor 3, Juli 2017.

Toni, Ahmad. (2016). Ideologi Film Garin Nugroho Kajian Semiotika Pada Film "Daun Di Atas Bantal". Jurnal Communication Vol. 7 Nomor 2 . Universitas Budi Luhur.

https://id.wikipedia.org/wiki/Konvensi_Keran gka_Kerja_Perubahan_Iklim_Perserikat an_Bangsa-Bangsa. Diakses pada 16.09.19, pukul 10.30 WIB.

https://www.liputan6.com/citizen6/read/40423 17/perubahan-iklim-itu-nyata-inipemakaman-untuk-glester-pertamayang-mencair-di-islandia. Diakses pada tanggal 16.09.19, pukul 09.02 WIB.

https://www.liputan6.com/global/read/367638 1/7-bencana-alam-mengerikan-inidipicu-pemanasan-global. Diakses pada
16.09.19, pukul 10.07 WIB

https://wri-indonesia.org/id/blog/negaranegara-asean-harus-mengambiltindakan-bersama-untuk-menghadapiperubahan-iklim. Diakses pada 16.09.19, pukul 10.21 WIB.

https://www.youtube.com/watch?v=nb-

IEclxd6k. Diakses pada tanggal 20.06.18, pukul 16.51 WIB

https://www.youtube.com/watch?v=S33Inv0G p1A. Diakses pada tanggal 20.06.18, pukul 20.18 WIB.

www.youtube.com/watch?v=WS7YZQqUG3 M. Diakses pada tanggal 24.10.17 pukul 18.29 WIB 